appear to overlook one important point. I am referring to the emotional distress and suffering which these patients undergo while they are waiting for the recovery which they may anticipate as the outcome of the " natural history" of their condition. Such suffering is particularly real and distressing in the anxiety, phobic, and depressive reaction-types. Cure and recovery are not the only objectives of treatment ; relief of distress and suffering is just as important in psychiatry as in other fields of medical practice. The danger of neglecting therapeutic measures such as psychotherapy, medication, environmental changes, etc., because one knows that "natural" recovery will take place in $70 \%$ of cases, must at all costs be avoided. One would also like to know how many of the $70 \%$ " recovered" because they submitted to the life struggle at a lower level of achievement than might otherwise have been anticipated.-I am, etc.,

$$
\begin{gathered}
\text { Port Elizabeth, } \\
\text { South Africa. }
\end{gathered}
$$

The apparatus is made as follows:

(1) Plastic Bottles.-These are the 2-litre containers for Micropaque suspension used in radiography. The bottles are non-returnable after use of the contents and are therefore freely available. They are obtained from the $x$-ray department, who should be supplied by Messrs. Damancy \& Co., Ware, Herts.

(2) Nylon Tubing.-Nylon 9 standard grade. Bore $6 \mathrm{~mm}$., external diameter 7.5 $\mathrm{mm}$. Required: 1 piece 3 in. $(7.6 \mathrm{~cm}$.) long, and 1 piece 12 in. $(30.5 \mathrm{~cm}$.) long (obtained from Portland Plastics Ltd., Hythe, Kent), 70s. per $30 \mathrm{ft}$. $(915 \mathrm{~cm}$.).

(3) Rubber Bungs.-Bungs No. 27, drilled with two holes to fit tubing (obtained from Messrs. Griffin \& George Ltd., Ealing Road, Alperton, Middlesex), 10s. per doz., drilled.

(4) Marking the bottle is done with Flashdry marker.

We offer our thanks to Mr. T. Gibson, who took the photograph.

-We are, etc.,

Hereford.

Hugh Davies. H. Clansey.

REPERENCE

\section{Urinary Drainage}

SIR,-Ashton Miller and his colleagues ${ }^{1}$ have shown that closed drainage should be used when a catheter is left in the bladder. Owing to frequent breakage of the glass bottles suitable for closed drainage, the cheap, unbreakable bottle described below was produced at this hospital. It has proved successful both for pre-operative and immediate post-operative drainage, and is popular with the nursing staff. It can be sterilized by boiling or by immersion in chemical solution, and is sufficiently light in weight to be carried about by the patient with ease.

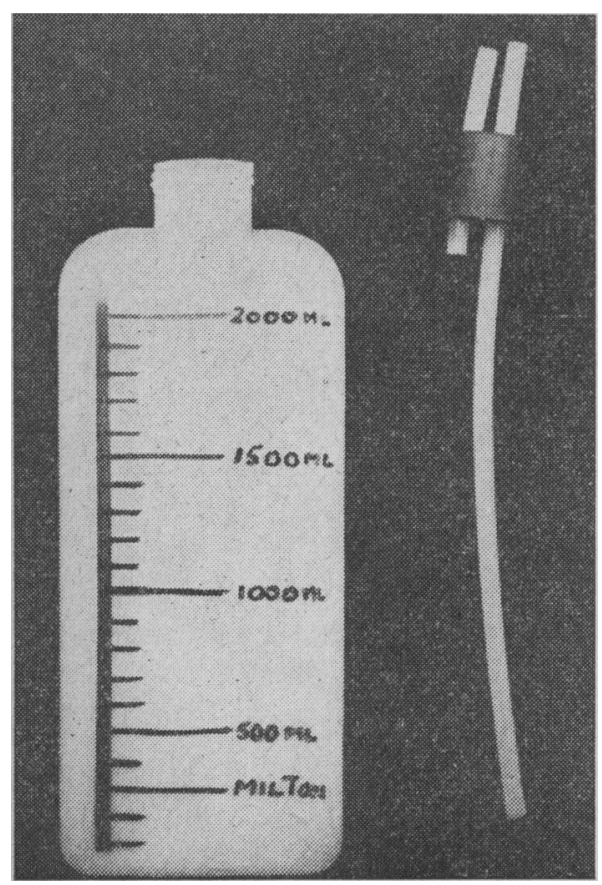

The only slight drawback is that it is translucent but not completely transparent, so that the colour of the urine cannot be determined with exactness; but this is not of great importance if a clear glass connector joins the indwelling catheter to the drainage apparatus.
Court in Wilmington, Delaware, with infringement of two patents used in making tetracycline (Drug News Weekly, July 8).
Would Mr. Wright seriously advise chemists not to stock Pfizer tetracycline until this case has been settled?

We believe that drugs can, and must, be produced on narrower profit margins. We have met some resistance to this idea, but we have also been heartened by the support we have received both from the medical and retail pharmaceutical professions.-I am, etc.,

M. C. Solomon,
Medical Director.
Chelsea Drug and Chemical
Company Limited,
London W.1.

\section{Fractures and $\mathrm{X}$-rays}

SIR,-While agreeing with Dr. B. G. F. Shepheard (15 August, p. 449) that for follow-up purposes the $x$-rays taken at the time of an injury are as important as an adequate record of the treatment given, I do not feel that it would be wise to send films by the hand of patients transferred from the casualty department of one hospital to the out-patient department of another.

In my recent experience as a casualty officer during a summer season in this busy resort I rendered the initial treatment to numerous injured holiday-makers. It was rare to find amongst these patients one who could remember even the address of his family doctor, let alone the name of his nearest hospital with an orthopaedic department. Had these patients taken their $x$-rays with them, there would have been no record of the ultimate destination of the films.

In the event of litigation arising out of either the injury or the treatment in such cases, the hospital giving the initial treatment would be in the embarrassing position of having no $x$-ray films and no radiologist's report to which they might refer.

I would suggest that it is more proper to send such patients away with a letter addressed to the family doctor, who in turn should refer his patient on to the orthopaedic surgeon of his choice. A simple postal request from the second hospital would secure the appropriate $x$-ray films by return post. Any competent appointments clerk could see to it that the $x$-rays were requested in time for the first consultation.-I am, etc.,

Bournemouth, Hants. Howard VAILE.

\section{"Mongolian" Spots}

SIR,-May I express full agreement with the opinion expressed by Dr. R. H. P. Clark regarding "Mongolian spots" (4 July, p. 57) that, contrary to what your expert wrote in the issue of 16 May (p. 1303), Mongolian spots are in fact very frequent in babies belonging to the "Mongolian" races?

I run a regular well-baby clinic in the midst of a population almost exclusively made up of people from the so-called "Mongolian races" (Malay and Chinese). Mongolian spots certainly do occur in the majority of infants seen at my clinic. I took a random sample at my last clinic session. Fifteen of the babies in the sample had Mongolian spots. Only three did not have definite Mongolian spots.-I am, etc.,

Pulau Bukom,
Singapore.

W. O. PhoON 